\title{
Fusarium spp. Incidence and DON Contamination in Different Wheat Varieties Correlated with the Environmental Factors
}

\author{
S. Popovski ${ }^{1 *}, \mathrm{~K} \mathrm{Kos}^{1}$, B. JaKovac $\mathrm{STRAJN}^{2}$ and F.A. CELAR ${ }^{1}$ \\ ${ }^{1}$ Biotechnical Faculty, Department of Agronomy, University of Ljubljana, Jamnikarjeva 101, \\ SI-1111 Ljubljana, Slovenia \\ ${ }^{2}$ Veterinary Faculty, Institute of Hygiene and Pathology of Animal Nutrition, University of Ljubljana, \\ Cesta v Mestni log 47, 1000 Ljubljana, Slovenia
}

(Received 28 April 2016; Accepted 3 August 2016)

\begin{abstract}
The genus Fusarium consists of multiple diverse species, which, as a result of their frequency in nature and pathogenicity, are significant in agriculture, as well as in human and veterinary medicine. In the course of field trials, by using standard phytopathological methods, and performing analyses of 19 different varieties of wheat and a portion of infected grains gathered from two distinct locations in Slovenia, we have determined the presence of various phytopathogenic species of the genus Fusarium. Because of the reliability, the experiment was performed in two consecutive years, 2012 and 2013. A laboratory analysis was conducted with an ELISA test on all grain samples for the determination of deoxynivalenol (DON) concentration. The results show that the main differences in the infection levels (F. culmorum $+F$. graminearum; $\mathrm{FC}+\mathrm{FG}$ ) of wheat samples were found in Jable (humid area), at the same time showing higher levels of DON content than Rakičan (dry area). Such a statement is supported by correlation test, where correlation is evident between FC+FG and DON in every variation. The data for both wheat types (awned and awnless) together showed that the grain in Jable is statistically significant more infected by FC+FG when compared to that in Rakičan. Moreover, our descriptive analysis confirms that the infection rate of grain with FC and FG shows a strong correlation with the emergence of DON.
\end{abstract}

Keywords: DON, environmental factors, field experiment, Fusarium spp., wheat varieties

\section{Introduction}

Fusarium head blight (FHB; also known as 'scab' or ear blight) is caused primarily by the fungus FG (teleomorph Gibberella zeae). It is a devastating disease on wheat capable of infecting the entire wheat host. FHB can lead to several losses in wheat quality, reduced seed germination, but also can reduce nutritional quality through contamination with mycotoxins (Mesterházy 2005). From an economical and environmental aspect, breeding resistant host plant (varieties) is one of the most appropriate methods to control FHB (Ruckenbauer et al. 2001). FG is a facultative parasite, that is, it ordinarily exists as a

\footnotetext{
*Corresponding author; E-mail: sasopopovski87@hotmail.com
} 
saprophyte but can live as a parasite on plants, causing disease (McMullen et al. 1997; Goswami and Kistler 2004).

The great financial significance is attributed to Fusarium diseases of wheat, which are responsible for major crop losses of yield on a global scale. The species of the Fusarium genus have also been known to generate a spectrum of toxic secondary metabolites, known as mycotoxins, which can lead to possible health risks in instances of contaminated grain consumption in both human and animal food products (D'Mello et al. 1999; Placinta et al. 1999).

The main Fusarium toxic secondary metabolite is deoxynivalenol (DON), produced chiefly by FG and FC, the most important European DON-producing fungi (Bottalico and Perrone 2002). DON incidence is likewise deemed to be an indicator of the probable presence of other, more toxic trichothecenes (Jajić et al. 2008), which might eventually lead to mycotoxicosis by ingestions of cereals and other products derived from Fusarium-infected grain (D'Mello and Macdonald 1997).

The purpose of the research was to determine whether there were any differences in ear infection levels between the various wheat varieties, correlated to the weather conditions during the flowering period, the wheat type and the location. Detailed laboratory analyses were conducted to determine whether there were any differences in grain infection and DON contamination in relation to the wheat variety, location, and year.

\section{Materials and Methods}

The macro field trials were conducted at two different locations in Slovenia, namely Rakičan and Jable. Both represent official experimental stations for testing new varieties of wheat and their introduction in the general production. The same crop rotation (maize-wheat) was used, for at least a 6-year period, to allow for a greater infection pressure carried by the Fusarium spp. In both years (2012 and 2013) and locations of the field trial, the fungicide Prosaro (prothioconazole + tebuconazole), a product of Bayer CS, was applied at a dosage of 1 liter per hectare at the beginning of wheat flowering (BBCH 61).

Rakičan $\left(46^{\circ} 38^{\prime} \mathrm{N}, 16^{\circ} 11^{\prime} \mathrm{E}\right.$, altitude: $\left.184 \mathrm{~m}\right)$ is located in the central part of the Prekmurje region, near Murska Sobota. The meteorological station of reference is the Murska Sobota station, also located in Rakičan. In the period 2011-2013, the average air temperature was $11^{\circ} \mathrm{C}$; average annual precipitation was $795.5 \mathrm{~mm}$ and typical district brown soil type on holocene gravel debris.

Jable (46 $8^{\prime} \mathrm{N}, 14^{\circ} 34^{\prime} \mathrm{E}$, altitude: $305 \mathrm{~m}$ ) is located in the central part of the Ljubljana basin, in pre-alpine Slovenia. The meteorological station of reference is the Brnik station. Average annual temperature (2011-2013) was $9.9^{\circ} \mathrm{C}$; average annual precipitation was $1218.9 \mathrm{~mm}$ and moderately clay soil type on a siliceous limestone base.

Monitoring was conducted at both test locations (2012-2013) to determine the length of the flowering of all 19 wheat varieties. Each of the sown samples represented a set of perspective varieties chosen for cultivation in Slovenia, different in origin, type and maturation period. Randomized block design for each wheat variety was $4 \times 25 \mathrm{~m}^{2}$ net value 
$\left(100 \mathrm{~m}^{2}\right)$. At both locations fertilization was done with $\mathrm{N}: \mathrm{P}: \mathrm{K}$ 5:15:30 $600 \mathrm{~kg} \mathrm{ha}^{-1}$ and urea $150 \mathrm{~kg} \mathrm{ha}^{-1}$. The number of replications was three. The test locations differ significantly regarding typical weather conditions, but above all regarding precipitation, which strongly favors the development of fusariosis. Each variety was separately catalogued in the database, a procedure of crucial significance in this research because the Fusarium spp. are the most infective at that stage of wheat development. In every plot, an integrated manner of wheat production was conducted. The percentile of Fusarium ear infection for each wheat variety was determined by the Stack and McMullen (1995) method. The laboratory analyses were carried out on individual grain samples for each wheat variety gaining an accurate representation of all Fusarium species.

\section{Statistical analyses}

Data collected were analyzed using statistical two-tail Student $t$-test and correlation coefficient. Samples from different populations and variance undergo Student $t$-test Type 3. Statistical analyses were performed using Microsoft Excel Data Analyst add-in.

\section{Identification of Fusarium spp.}

Over the course of the two-year growing period, 19 samples of different wheat varieties were collected from each of the two distinct locations, continuously. After harvest, all the samples were taken from $30 \mathrm{~kg}$ sacks in a total of $2 \mathrm{~kg}$, half of which was used for mycotoxin analysis, and the other half was used for Fusarium spp. laboratory identification. In the laboratory, 100 randomly selected wheat grains were surface-disinfected with $1 \%$ sodium hypochlorite $(\mathrm{NaOCl})$ in Erlenmeyer flasks for 10 minutes, and further rinsed with sterile distilled water and dried on previously sterilized paper.

Five grains were placed under sterile conditions in each of the 20 Petri dishes, $90 \mathrm{~mm}$ in diameter, containing $15 \mathrm{~mL}$ of modified potato dextrose agar (PDA) medium: $14 \mathrm{~g}$ of potato dextrose agar (Biolife), $10 \mathrm{~g}$ technical agar (Biolife), $0.121 \mathrm{~g}$ penicillin $\mathrm{G}$ (Merck), and $0.542 \mathrm{~g}$ streptomycin sulfate (Merck) per liter. They were further incubated under dark conditions at $20^{\circ} \mathrm{C}$, RH $60 \%$, for the period of 7 days, while being observed daily. Following the incubation period, each fungal colony was examined microscopically for identification at genus or species level. The microscopic observations being carried out under 100 and $\times 400$ magnification (Zeiss Axio Scope, Germany). The focus of the observations was on macroconidia morphology, the presence/absence of microconidia and chlamydospores, as well as sporodochia production. In certain cases, due to reliable identification of individual species of fungi, the fragments of colonies developed on seeds and the medium were transferred to carnation leaf agar (CLA) and synthetic nutrition agar (SNA) and incubated at $12 \mathrm{~h}$ day/night regime, using combined fluorescent and near ultraviolet light during the daytime period. The CLA and SNA media were prepared according to Burgess et al. (1994) and Nirenberg (1976), respectively. Identification was performed by utilizing the keys of Gerlach and Nirenberg (1982), Burgess et al. (1994) and Leslie and Summerell (2006), noting the considerations of Summerell et al. (2003). The 
mycelia and spores identified as Fusarium spp. were used to establish pure cultures on potato dextrose agar (PDA) and deposited in the refrigerator for the purpose of additional surveys.

\section{ELISA for the determination of DON}

The other half of the grain samples were analyzed for DON content by using an ELISA, Ridascreen ${ }^{\circledR}$ Fast DON. The process consisted of the following steps. Firstly, a $20 \mathrm{~g}$ sample was taken from the main sample $(1 \mathrm{~kg})$ and put into a $250 \mathrm{~mL}$ extraction flask and then $100 \mathrm{~mL}$ of deionized water was added. After an hour of stirring and filtering the extract, $1 \mathrm{~mL}$ was poured into a tube and diluted with $3 \mathrm{~mL}$ of deionized water. Using a microtiter plate, we applied $200 \mu \mathrm{L}$ of the conjugate, then $100 \mu \mathrm{L}$ of the extract solution in the designated spots. The mixture was moved to a different microtiter plate that contained antibodies and left for 15 minutes. We further washed the plate with a mild detergent solution and added another $100 \mu \mathrm{L}$ of the substrate, leaving it for 5 minutes, and then adding another $100 \mu \mathrm{L}$ of the mild detergent solution to stop the reaction. The DON levels were measured with an ELISA reader.

\section{Results}

During the flowering period for 2012 in Rakičan, a minimum of $0.1 \mathrm{~mm}$, a maximum of $52.9 \mathrm{~mm}$, and a median value of $15.4 \mathrm{~mm}$ of rainfall was observed. The median number of rainy days was 2 . The minimal, maximal and median temperatures for the same period were $10.5^{\circ} \mathrm{C}, 17.9^{\circ} \mathrm{C}$, and $13.7^{\circ} \mathrm{C}$, respectively.

The weather conditions during the flowering period in Rakičan were quite different in 2013 from the same period of the previous year. The minimum amount of rainfall was 0.0 $\mathrm{mm}$, the maximum $16.5 \mathrm{~mm}$ and the median data was $5.1 \mathrm{~mm}$. The median for rainy days was 2 . The minimum, maximum and median temperatures during the same period were $12.4{ }^{\circ} \mathrm{C}, 17.3{ }^{\circ} \mathrm{C}$ and $15.6{ }^{\circ} \mathrm{C}$, respectively (Table S1*). According to the observations and their descriptive statistics, no correlation was observed at this location for 2012 and 2013 between the weather conditions and the incidence of Fusarium head blight. Consequently, there is no direct influence of the total amount of precipitation during flowering and temperature on the average levels of ear infection (Figs S1 and S2).

The acquired data of the wheat flowering period for 2012 in Jable showed a significant difference in precipitation as opposed to Rakičan. The minimum amount of rainfall was $1.5 \mathrm{~mm}$; the maximum was $40.1 \mathrm{~mm}$, and the median data amounted to $34.7 \mathrm{~mm}$. The median for rainy days during flowering was 5 . The minimum, maximum and median temperatures for the same period were $13.3{ }^{\circ} \mathrm{C}, 17.2{ }^{\circ} \mathrm{C}$ and $15.3{ }^{\circ} \mathrm{C}$, respectively. In 2013, the minimum amount of rainfall was $44.0 \mathrm{~mm}$, the maximum was $114.9 \mathrm{~mm}$, and the median was $72.1 \mathrm{~mm}$, respectively. The median for rainy days during flowering in 2013 was 8 . The minimum, maximum and median temperatures during the same period

*Further details about the Electronic Supplementary Material (ESM) can be found at the end of the article. 
were $12.6{ }^{\circ} \mathrm{C}, 20.6{ }^{\circ} \mathrm{C}$ and $15.5^{\circ} \mathrm{C}$, respectively (Table S2). For both years in Jable, the descriptive statistics show no correlation between temperature and precipitation on one side and wheat's ear infection on the other, during the flowering period, which was the same as in Rakičan (Figs S1 and S2).

Regarding wheat type, no statistical difference was detected between awned and awnless wheat, based on data on an average ear infection. The same results were obtained when both wheat types were considered over both locations. Due to the unequal ratio (6 awned : 13 awnless) of the wheat types, the results were not generalized.

A part of the grain samples was used for grain analysis. The analysis aimed for the grain infection with FC and FG as well as DON contamination. The results of the analyzed samples are presented in Table S3.

The results obtained from Rakičan in 2012 show an average infestation rate of $0.2 \%$ of FC and $2.1 \%$ of FG. (Table S3). In 2013, the average presence of FC was $1.1 \%$, while the presence of FG was decreased to $1.6 \%$ (Table S3). The data analysis from Rakičan based on $\mathrm{FC}+\mathrm{FG}$ presence showed that the awned wheat had statistically significant smaller infection levels when compared to the awnless wheat (Table 1). The data for both wheat types revealed that FC + FG significantly infected the grain more in Jable than in Rakičan.

Two positive samples passed the detected limit of $200 \mu \mathrm{g} / \mathrm{kg}$ DON in Rakičan in 2012. The maximum DON content detected in 2012 was $297 \mu \mathrm{g} / \mathrm{kg}$. One positive sample was detected in 2013, with a maximum DON content of $1033 \mu \mathrm{g} / \mathrm{kg}$. The total mean value for the DON content in 2012 was $140 \mu \mathrm{g} / \mathrm{kg}$, and $120 \mu \mathrm{g} / \mathrm{kg}$ in 2013 . The limit of $1250 \mu \mathrm{g} / \mathrm{kg}$ imposed by the European Union (EU) for DON content was not exceeded in the analyzed samples. The results indicate that DON presence in Rakičan was at a low level during 2012 and 2013 (Table S3).

The results from Jable in 2012 present an entirely different picture in the occurrence of Fusarium spp. and DON contamination. The average presence of FC was $0.5 \%$, and the average of FG was 8.9\% (Table S3). In 2013, the presence of FC was higher than 2012 with an average of $1.3 \%$, while the average of FG occurrence had decreased to $3.5 \%$ (Table S3). The statistical analysis of the data from Jable showed that there was no statistically significant difference between awned and awnless wheat in relation to $\mathrm{FC}+\mathrm{FG}$ presence (Table 1).

Table 1. Two-tailed $t$-test of type 3 for both types of wheat based on the data of grain infection with FC $+\mathrm{FG}$ (data for both locations and years), with significance level $\alpha=0.05$

\begin{tabular}{|c|c|c|c|c|c|c|c|c|}
\hline Location & \multicolumn{2}{|c|}{ Rakičan and Jable } & \multicolumn{2}{|c|}{ Rakičan } & \multicolumn{2}{|c|}{ Jable } & Rakičan & Jable \\
\hline Wheat types & $\begin{array}{c}\text { Awnless } \\
\text { wheat }\end{array}$ & $\begin{array}{c}\text { Awned } \\
\text { wheat }\end{array}$ & $\begin{array}{c}\text { Awnless } \\
\text { wheat }\end{array}$ & $\begin{array}{c}\text { Awned } \\
\text { wheat }\end{array}$ & $\begin{array}{c}\text { Awnless } \\
\text { wheat }\end{array}$ & $\begin{array}{c}\text { Awned } \\
\text { wheat }\end{array}$ & $\begin{array}{c}\text { Both } \\
\text { awl+aw }\end{array}$ & $\begin{array}{c}\text { Both } \\
\text { awl+aw }\end{array}$ \\
\hline Mean & 4.81 & 4.66 & 2.81 & 1.66 & 6.81 & 7.66 & 2.45 & 7.08 \\
\hline Std Dev & 5.17 & 6.71 & 2.19 & 0.89 & 6.44 & 8.59 & 1.94 & 7.08 \\
\hline df & \multicolumn{2}{|c|}{74} & \multicolumn{2}{|c|}{36} & \multicolumn{2}{|c|}{36} & \multicolumn{2}{|c|}{74} \\
\hline$p$-value & \multicolumn{2}{|c|}{0.93} & \multicolumn{2}{|c|}{$0.029 *$} & \multicolumn{2}{|c|}{0.76} & \multicolumn{2}{|c|}{$0.00015^{*}$} \\
\hline
\end{tabular}

$\mathrm{FC}+\mathrm{FG}-F$. culmorum + F. graminearum; Std Dev - standard deviation; df - degrees of freedom; *statistical significant difference; awl - awnless wheat; aw - awned wheat 
In 2012, 16 positive samples passed the detected limit of $200 \mu \mathrm{g} / \mathrm{kg}$ DON in Jable. The maximum DON content detected in 2012 was $3550 \mu \mathrm{g} / \mathrm{kg}$. In 2013, 16 samples were also detected, with a maximum DON content of $2905 \mu \mathrm{g} / \mathrm{kg}$. The total mean value for DON in 2012 was $714 \mu \mathrm{g} / \mathrm{kg}$ and $684 \mu \mathrm{g} / \mathrm{kg}$ in 2013 . The limit of $1250 \mu \mathrm{g} / \mathrm{kg}$ imposed by the European Union (EU) for DON content was exceeded in two samples in Jable in both 2012 and 2013 (Table S3).

A linear correlation $(\mathrm{r}=0.68)$ was observed between FC + FG and DON (Fig. S3) over data from the Rakičan location $\left(\mathrm{y}=56.742 \mathrm{x}-8.8426, \mathrm{r}^{2}=0.46\right)$. A linear correlation $(\mathrm{r}=0.64)$ was also found between FC + FG and DON (Fig. S4) in Jable $(y=69.507 x+$ 207.1, $\mathrm{r}^{2}=0.41$ ). By combining the data from both locations (Rakičan and Jable) and both years (2012 and 2013), the highest correlation $r=0.71$ (Fig. S5) was detected, with the correlation function $\mathrm{y}=77.816 \mathrm{x}+43.931, \mathrm{r}^{2}=0.51$.

\section{Discussion}

This research was conducted with the purpose to analyze the Fusarium spp. incidence and DON contamination in different wheat varieties correlated with the environmental factors. Through relevant field analyses and laboratory tests, this two-year research work generated valuable information about the Fusarium spp. encountered in Slovenia (Rakičan-Jable) on naturally infected wheat and their contamination with DON.

In general, the most often isolated Fusarium species from wheat samples were $F$. graminearum, $F$. culmorum, $F$. poae and $F$. avenaceum. These species are pathogenic on wheat ears, causing head blight and mycotoxin contamination of the grain (Parry et al. 1995). With determining the percentile of FHB of each wheat variety individually, by Stack and McMullen's method (1995), it was impossible to predict the mycotoxin contamination by field estimates.

According to the data from the meteorological stations, a far greater intensity of rain was recorded in Jable continuously over the two-year trial period as compared to Rakičan. Regardless of the retrieved data, from the descriptive statistics, no correlation has been determined over both locations for 2012 and 2013 between the weather conditions (temperature/precipitation) and the incidence of Fusarium head blight. Consequently, we can also conclude that there is no direct influence of the total amount of precipitation and temperature during flowering on the average levels of ear infection (Figs S1 and S2). These results differ from the results of some other researchers, from the point of view that perhaps there is some other factor besides the environmental conditions responsible for the occurrence of Fusarium spp. To be sure in our statement an additional correlation test was conducted between the weather conditions (temperature/precipitation) during flowering and grain contamination with DON. Repeatedly, the same conclusion was confirmed, i.e. a low correlation coefficient was observed $(r=0.41$ and $r=0.14$ for temperature and precipitation, respectively) in both locations for 2012 and 2013. A similar conclusion was also confirmed by the correlation test between the weather conditions (temperature/precipitation) during flowering and grain infection with $\mathrm{FC}+\mathrm{FG}(\mathrm{r}=0.20$ and $\mathrm{r}=0.09$ for 
temperature and precipitation, respectively) in both locations for 2012 and 2013. Even in both variations, the descriptive statistics have confirmed the impact of other factors responsible for the grain infection with FC + FG and the appearance of DON in grains, besides the weather during the flowering period, even later on in vegetation. Blandino et al. (2012) pointed out that FHB infection and DON contamination of wheat grains can be caused by different factors, while the climatic conditions remain the main factor, but also from agronomic factors such as previous crop residue management, cultivar susceptibility, and fungicide applications. Eiblmeier and von Gleissenthall (2007) gave a similar statement that the climatic conditions during the flowering period, preceding crop, no or minimal tillage, susceptible cultivar, strobilurin as a foliar fungicide and late harvest are considered to be risk factors for increasing levels of DON in wheat grains.

As a result of the specificity of the environmental factors in Jable, the high intensity of the wheat grain infection caused by FG and FC led to a high level of DON contamination. 16 out of 19 samples (2012-2013) showed mycotoxin concentrations above the lower detected limit of $200 \mu \mathrm{g} / \mathrm{kg}$, but also, two samples in 2012 and 2013 managed to exceed the maximum limit of $1250 \mu \mathrm{g} / \mathrm{kg}$ [Commission Regulation (EC) No 1126/2007 of $28^{\text {th }}$ September 2007], which confirmed the close connection between the presence of FG and FC with the occurrence of DON (Table S3). On the other hand, the Rakičan precipitation was more moderate, resulting in minimal infection caused by FG and FC, and therefore a lower DON contamination. In 2012, there were only two varieties of wheat that exceeded the minimum threshold for DON, while in 2013 only one case was registered. The maximum limit for DON content was not exceeded in the analysed samples in the two-year experimental period (Table S3).

The main differences in the infection levels $(\mathrm{FC}+\mathrm{FG})$ of wheat samples were found in Jable, which represents a typical humid area, at the same time showing higher levels of DON content than Rakičan, which is a dry area, the complete opposite of Jable. Such a statement is supported by correlation test, where a correlation is evident between FC $+\mathrm{FG}$ and DON for every location separately, as well as for both locations together (Figs S3, S4, and S5). Moreover, our descriptive analysis of discovering the major factors that influence the appearance of DON confirms that the infection rate of grain with FG and FC shows a strong correlation with the emergence of DON.

However, the different levels of mycotoxin contamination between these years were more affected by rainfall than by temperature. It is hard to infer trends or recent developments regarding high DON contamination in grains, because the occurrence of contaminated samples, as well as the environmental factors, is also influenced by many other factors (Koch et al. 2006; Škrbič et al. 2012; Wegulo 2012). Therefore an integrated approach to the disease is appropriate to reduce the risk of high DON contamination in wheat grains. Also, an ear infection cannot be straightforwardly interpreted as a potential insight in grain infection. Contamination levels might also be associated with factors other than climate conditions, such as with mycotoxin formation, crop rotation (maize as a pre-crop for wheat), and growing highly susceptible wheat varieties with no applied fungicide. To obtain further insight into Fusarium spp. incidence and DON contamina- 
tion, additional wheat research is necessary to control food and feed quality. Additionally, to increase the FHB resistance and crop yield, relevant wheat varieties should be preferred for cultivation in Slovenia.

\section{Acknowledgements}

The authors would like to thank Dr. Igor Šantavec for his very helpful advice, enthusiasm, and comments on this work. We are also grateful for the financial support provided by the Slovenian Research Agency, Ministry of Agriculture, Forestry and Food and Ad Futura Foundation.

\section{References}

Blandino, M., Haidukowski, M., Pascale, M., Plizzari, L., Scudellari, D., Reyneri, A. 2012. Integrated strategies for the control of Fusarium head blight and deoxynivalenol contamination in winter wheat. Field Crop Res. 133:139-149.

Bottalico, A., Perrone, G. 2002. Toxigenic Fusarium species and mycotoxins associated with heat blight in small-grain cereal in Europe. Eur. J. Plant Pathol. 108:611-624.

Burgess, L.W., Summerell, B.A., Bullock, S., Gott, K.P., Backhouse, D. 1994. Laboratory manual for Fusarium research. 3rd ed. University of Sydney and Botanic Garden. Sydney, Australia

Commission Regulation 2007. (EC) No 1126/2007 of 28 September 2007 amending Regulation (EC) No $1881 / 2006$ setting maximum levels for certain contaminants in foodstuffs as regards Fusarium toxins in maize and maize products. Off. J. Eur. Union 2007, L255. 50:14-17. (accessed 15.06.14) http://eur-lex. europa.eu/legal-content/EN/TXT/?uri=OJ:L:2007:255:TOC

D’Mello, J.P.F., Macdonald, A.M.C. 1997. Mycotoxins. Animal Feed Sci. and Technol. 69:155-166.

D’Mello, J.P.F., Placinta, C.M., Macdonald, A.M.C. 1999. Fusarium mycotoxins: A review of global implications for animal health, welfare and productivity. Animal Feed Sci. and Technol. 80:183-205.

Eiblmeier, P., Von Gleissenthall, J.L. 2007. Risk evaluation of deoxynivalenol levels in Bavarian wheat from survey data. J. Plant Dis. and Protec. 114:69-75.

Gerlach, W., Nirenberg, H. 1982. The genus Fusarium a pictorial atlas. Mitteilungen aus der Biologischen Bundesanstalt für Land- und Forstwirtschaft. Berlin-Dahlem, Germany.

Goswami, R.S., Kistler, H.C. 2004. Heading for disaster: Fusarium graminearum on cereal crops. Mol. Plant Pathol. 5:515-525.

Ireta, M.J., Gilchrist, L. 1994. Fusarium head scab of wheat (Fusarium graminearum Schwabe). Wheat Special Report No. 21b. CIMMYT. Mexico, DF, Mexico.

Jajić, I., Jurić, V., Glamočić, D., Abramović, B. 2008. Occurrence of deoxynivalenol in maize and wheat in Serbia. Int. J. Mol. Sci. 9:2114-2126.

Koch, H.J., Pringas, C., Maerlaender, B. 2006. Evaluation of environmental and management effects on Fusarium head blight infection and deoxynivalenol concentration in the grain of winter wheat. Eur. J. Agron. 24:357-366.

Leslie, J.F., Summerell, B.A. 2006. The Fusarium Laboratory Manual, 1st edn.. Blackwell Publishing. Ames, IA, USA. 388 p.

McMullen, M., Jones, R., Gallenberg, D. 1997. Scab of wheat and barley: A re-emerging disease of devastating impact. Plant Dis. 81:1340-1348.

Mesterházy, Á. 1987. Selection of head blight resistant wheats through improved seedling resistance. Plant Breed. 98:25-36.

Mesterházy, Á. 2005. Common resistance to different Fusarium spp. causing Fusarium head blight in wheat. Eur. J. Plant Pathol. 112:267-281. 
Nirenberg, H.I. 1976. Untersuchungen über die morphologische und biologische Differenzierung in der Fusarium-Section Liseola. Mitteilungen aus der Biologischen Bundesanstalt für Land-Forstwirtschaft, Berlin-Dahlem. (Studies on the morphological and biological differentiation in the Fusarium-section Liseola. Reports from Federal Centre of Biology for Agriculture and Forestry, Berlin-Dahlem.) 169:1-117. (in German)

Obermayer, E. 1916. Untersuchungen über das Blühen und die Befruchtung von Winterroggen und Winterweizen. (Studies on flowering and fertilization of winter rye and winter wheat.) Zschr. Pflanzenz. 4:347-403. (in German)

Parry, D.W., Jenkinson, P., McLeod, L. 1995. Fusarium ear blight (scab) in small-grain cereals - a review. Plant Pathol. 44:207-238.

Placinta, C.M., D’Mello, J.P.F., Macdonald, A.M.C. 1999. A review of worldwide contamination of cereal grains and animal feed with Fusarium mycotoxins. Animal Feed Sci. and Technol. 78:21-37.

Ruckenbauer, P., Buerstmayr, H., Lemmens, M. 2001. Present strategies in resistance breeding against scab (Fusarium spp.). Euphytica 119:121-127.

Škrbič, B., Živančev, J., Durišić-Mladenović, N., Godulab, M. 2012. Principal mycotoxins in wheat flour from the Serbian market: Levels and assessment of the exposure by wheat-based products. Food Control 25:389396.

Stack, R.W., McMullen, M. 1995. A visual scale to estimate severity of Fusarium head blight of wheat, North Dakota State University. PP-1095, 2 p. (accessed 20.06.14) https://www.ag.ndsu.edu/pubs/plantsci/ smgrains/pp1095.pdf

Summerell, B.A., Salleh, B., Leslie, J.F. 2003. A utilitarian approach to Fusarium identification. Plant Dis. 87:117-28.

Wegulo, S.N. 2012. Factors influencing deoxynivalenol accumulation in small grain cereals. Toxins 4:11571180.

\section{Electronic Supplementary Material (ESM)}

Electronic Supplementary Material (ESM) associated with this article can be found at the website of CRC at http://www.akademiai.com/content/120427/

Electronic Supplementary Table S1. Average amount of rainy days, total rainfall during flowering, ear infection and average temperature during anthesis on 19 different varieties of wheat for Rakičan in years 2012 and 2013

Electronic Supplementary Table S2. Average amount of rainy days, total rainfall during flowering, ear infection and average temperature during anthesis on 19 different varieties of wheat for Jable in years 2012 and 2013

Electronic Supplementary Table S3. DON content $(\mu \mathrm{g} / \mathrm{kg})$ and percentage representation of Fusarium culmorum and Fusarium graminearum in 19 different wheat varieties from Rakičan and Jable in 2012 and 2013

Electronic Supplementary Figure S1. Visual comparison of the records between AEI (average ear infection) and TRF (total rainfall during flowering) on 19 different wheat varieties for Rakičan and Jable in 2012 and 2013

Electronic Supplementary Figure S2. Visual comparison of the records between AEI (average ear infection) and Temp (average temperature during flowering) on 19 different wheat varieties for Rakičan and Jable in 2012 and 2013

Electronic Supplementary Figure S3. Correlation between grains infection with FC+FG (F. culmorum + F. graminearum) and DON content on 19 different wheat varieties for Rakičan in years 2012 and 2013 (y-DON $\mu \mathrm{g} / \mathrm{kg}, \mathrm{x}$-grain infested with $\mathrm{FC}+\mathrm{FG}$ in \%) 
Electronic Supplementary Figure S4. Correlation between grains infection with FC+FG (F. culmorum $+F$. graminearum) and DON content on 19 different wheat varieties for Jable in years 2012 and 2013 (y-DON $\mu \mathrm{g}$ / $\mathrm{kg}, \mathrm{x}$-grain infested with $\mathrm{FC}+\mathrm{FG}$ in \%)

Electronic Supplementary Figure S5. Correlation between grains infection with FC+FG (F. culmorum $+F$. graminearum) and DON content on 19 different wheat varieties for both locations Rakičan/Jable in years 2012 and 2013 (y-DON $\mu \mathrm{g} / \mathrm{kg}$, x-grain infested with FC+FG in \%) 